\title{
Editorial
}

\section{Online sexual exploitation of children}

\author{
Mark Small *, Jason Pope \\ Clemson University, Institute on Family and Neighborhood Life, Clemson, South Carolina, USA
}

\section{Introduction}

There are dark places in the worldwide web where evil resides. Across the internet, a new form of online sexual exploitation of children is taking up residence in these dark places. The manufacturing and distribution of child abuse images online has long been a problem, but a new form of child abuse exploits children by live streaming their sexual acts. Directed by traffickers as well as online viewers, a child is instructed to pose and perform specified acts in front of a camera.

This new form of abuse of children presents complicated challenges for those interested in protecting children. For law enforcement professionals, there are two problems. Prosecuting those who lure children into this new form of online sexual exploitation is difficult because perpetrators are often family members or persons who are well known to the children. Indeed, one study shows that a significant number are mothers, acting out of their own homes (Hernandez, et al., 2018). Along with individual and family run operations, the most common operations are "dens", where large scale operations involve organized group operations that hire or traffic children (Hernandez et al., 2018). Given that all that is needed is a computer and camera, finding any of these places is difficult.

A second problem is jurisdictional. Because those who are viewing online may be from anywhere in the world, there is considerable expense and hassle to engage law enforcement from other countries to locate, track down, and prove viewership. For example, the broadcasting technology typically uses encryption and anonymity, and viewership may take place in internet cafes. Moreover, the viewers are not the usual suspects. One study revealed that online sexual perpetrators, compared to offline perpetrators, are less likely to have criminal backgrounds and prior anti-social histories (DeMarco et al., 2018).

For social workers and mental health professionals, online sexual exploitation of children is a case of human trafficking with special family considerations. As with other forms of human trafficking, poverty is the greatest risk factor. For families choosing between selling their children to traffickers or selling their children online themselves, the decision may be as simple as whether they possess the capability of managing a website and Paypal account. Indeed, there are anecdotal ac- counts of young teens managing their own websites and Paypal accounts. As the spread of inexpensive technology becomes more widespread among the poor, there is likely to be an increase in familial online sexual exploitation of children.

Another special consideration of online sexual exploitation of children is how treatment services should be structured. A child acting before a camera presents a much different scenario than the traditional sexual abuse involving physical contact. In a pioneering study of the impact of online sexual exploitation of children, Terre des Hommes Netherlands (2013) found that the initial impacts of child abuse included fear, anxiety, depression and hostility. Meanwhile, academic and behavioral problems, depression and internalizing difficulties were also commonly noted in school-aged children, along with decreased self-esteem, and suicidal ideation and feelings. The findings are preliminary and future research may document more specific harm resulting from this new type of exploitation.

As noted by Small (2015, p. 66), an unresolved question is whether specialized services are necessary for victims of human trafficking or whether the provision of typical services for post-traumatic stress disorder and other general trauma therapies are sufficient to meet the therapeutic needs of victims. In other words, does the harm caused by victimization through human trafficking constitute a new type of harm, deserving of a specialized therapeutic treatment approach or can the current social services and related therapies adequately help victims recover.

This question takes on additional meaning for victims of online sexual exploitation. For example, how is the harm of performing sexual acts under the guidance of family members in one's own home different from the harm associated with other forms of sexual exploitation, online or otherwise?

For researchers, the questions are easy but getting the answers is difficult. Answering the most basic question - What is the extent of online sexual exploitation of children? - depends on county specific data collection. To date, Southeast Asia, especially the Philippines, appears to be where a concentration of online sexual exploitation occurs (Hernandez et al., 2018), but because online sexual exploitation of children is a next level stage of development for child pornography websites, the servers may be in any country.

\footnotetext{
* Author for correspondence: Mark Small, Clemson University, Institute on Family and Neighborhood Life, 321 Brackett Hall, Clemson, South Carolina, 29634, USA; e-mail: msmall@clemson.edu http://doi.org/10.32725/kont.2019.019 
Other research questions are even more difficult. What prevention measures can be taken? What intervention measures might be effective? And the most difficult of all is a policy question - How to address the levels of poverty where parents, or even children themselves, see this activity as a viable lifestyle? Research documenting the short- and long-term consequences for children engaged in such activity is the best chance for convincing parents to seek other alternatives.

\section{References}

1. DeMarco J, Sharrock S, Crowther T, Barnard M (2018). Behaviour and characteristics of perpetrators of onlinefacilitated child sexual abuse and exploitation: a rapid evidence assessment. Final report. [online] [cit. 2018-03-10].
Available from: https://www.iicsa.org.uk/key-documents/3720/ view/rapid-evidence-assessment-behaviour-characteristicsperpetrators-online-facilitated-child-sexual-abuse-exploitation. pdf

2. Hernandez S, Lacsina A, Ylade M, Aldaba J, Lam H, Estacio L, Lopez A (2018). Sexual exploitation and abuse of children online in the Philippines: a review of online news and articles. Acta Medica Philipina 52(4): 305-311.

3. Small MA (2015). Human trafficking matters: Next steps. Kontakt 17(2): 65-66.

4. Terre des Hommes Netherlands (2013). Full screen on View: an exploratory study on the background and psychosocial consequences of webcam child sex tourism in the Philippines. [online] [cit. 2017-09-01]. Available from: https://www. mensenhandelweb.nl/en/system/files/documents/02\%20 apr\%202015/Sweetie\%20-\%20Background\%20and\%20 psychological\%20impact\%20of\%20webcam\%20child\%20 sex\%20tourism.pdf 